\title{
Utilization and Usability of Delaware Traffic Management Products: A Survey and Challenges
}

\author{
Ardeshir Faghri', Michael L. Vaughan ${ }^{2}$, Abebaw Berihun' ${ }^{1}$ \\ ${ }^{1}$ Department of Civil \& Environmental Engineering, University of Delaware, Newark, DE, USA \\ ${ }^{2}$ Office of the Interim Vice Provost for Diversity \& Inclusion, University of Delaware, Newark, DE, USA \\ Email: faghri@udel.edu,vaughan@udel.edu, abebaw@udel.edu
}

How to cite this paper: Faghri, A., Vaughan, M.L. and Berihun, A. (2021) Utilization and Usability of Delaware Traffic Management Products: A Survey and Challenges. Journal of Transportation Technologies, 11, 335-356.

https://doi.org/10.4236/jtts.2021.113022

Received: April 20, 2021

Accepted: June 5, 2021

Published: June 8, 2021

Copyright $\odot 2021$ by author(s) and Scientific Research Publishing Inc. This work is licensed under the Creative Commons Attribution International License (CC BY 4.0).

http://creativecommons.org/licenses/by/4.0/

\begin{abstract}
To address the growing problem of congestion, delays, and overall traffic issues, DelDOT (Delaware Department of Transportation) established the Transportation Management Center (TMC) in 1997. DelDOT-TMC also coordinates and manages DelDOT's response to any incident that impacts the multimodal transportation system within the state of Delaware. Among other things, DelDOT-TMC collects traffic, roadway weather, and hydrological data using over a thousand monitoring devices installed throughout the state of Delaware. After data has been obtained, DelDOT-TMC analyzes and disseminates real-time travel information to the public through DelDOT's website (online interactive maps), smartphone application, traffic advisory radio, and social media sites such as Twitter, Facebook, YouTube, Blog, and Flickr; however, the utilization and usability of this information by the public are, for the most part, unknown. The purpose of this study is to evaluate the global responsibilities of DelDOT-TMC and assess the process that DelDOT-TMC uses to gather, process, analyze, and distribute traffic and roadway weather data to the public. The study employs a survey to assess the utilization of DelDOT-TMC's products, i.e., DelDOT Mobile App, WTMC 1380 AM travel advisory radio, DelDOT's public website, DelDOT's social media, as well as the usability of the DelDOT mobile app to check DART (Delaware Authority for Regional Transportation) First State transit service schedules.
\end{abstract}

\section{Keywords}

Transportation Management Center, Survey, Questionnaire, Case Study

\section{Introduction}

Motor vehicles continue to be the primary transportation means within the 
United States and many parts of the world. The present and future dominance of motor vehicle transportation are undeniable. It follows then that problems such as congestion, delay, pollution, safety and parking will continue to occur [1]-[10]. To solve the transportation problems and improve transportation facilities and services, it is critical to understand the magnitude and the location of issues, as well as any associated need for improvement. Such understanding comes from accurate traffic data collection [11]-[16].

Traffic data is an essential element in programming, planning, designing, and evaluating the performance of individual roads (AADT and axle-load data) as well as the entire road system (vehicle-miles of travel, or "VMT"), pavement conditions [17] and performance of transit facilities [15] [16] [17] [18] [19]. When conducting a highway performance measure, traffic data can often be a useful tool for users such as the Department of Transportation, metropolitan/local planning, the Federal Highway Administration (FHWA), and the general public [12].

DelDOT has been responsible for maintaining the majority of the state's public roadways since 1917. Managing the state's traffic conditions is one of the DelDOT's primary responsibilities. To operate the state's transportation efficiently, DelDOT announced its initial integrated transportation management strategic plan in 1997, seeking to reduce congestion and delay, increase safety, reduce operating costs, and improve systems' performance [13]. The 1997 strategic plan acknowledged different strategies with associated actions to monitor the implementation of transportation management in the State of Delaware. Implementing a centralized TMC was the primary goal set by the department to create the necessary infrastructure to support the state's transportation management team [13].

Through DelDOT-TMC, a series of strategic plans were developed to provide safe and accurate traffic data. The first strategic plan was to disseminate accurate real-time traffic information so that users could make informed decisions concerning travel route, travel time, and modal choice. The second strategy was to develop partnerships with County Emergency Operations Centers (EOCs) and State Police to support transportation management activities. By doing so, DelDOT would be able to implement a coordinated and timely incident response. Further, DelDOT would have the opportunity to partner with the private sector, counties, and local agencies. Developing an internal capacity to support transportation management by providing staff training and organizational structure was identified as the third strategic plan [13].

DelDOT established and started operating a full-time centralized TMC in 2002. DelDOT-TMC was found to be the center for a databank, meaning that it would be the primary traffic and roadway weather data source for different divisions within DelDOT. Currently, DelDOT-TMC is a 24 -hour a day, 365 -day a year statewide operating system that coordinates and manages DelDOT's response to any incidents or events that influence the multimodal transportation system within the state of Delaware [13]. 
The TMC continually updates the original strategic plan with the same goals that were set in 1997. The updates will allow DelDOT-TMC to work towards the original goals that include creating infrastructures, disseminating real-time information, developing a partnership, and developing internal capacity to support the state's transportation management [13].

DelDOT-TMC provides real-time traffic, weather, and other information through the previously cited resources. The data can be used for simulation model input and for completing project study reports and other types of transportation planning and analysis documents [20] [21] [22] [23] [24]. There are many websites and mobile applications that provide real-time traffic and weather information. This study will examine the utilization and usability of DelDOT-TMC products such as the DelDOT Mobile App, travel advisory radio, DelDOT public website, and various social media sites for travel information.

This paper is organized as follows. Section 2 examines multi-state data source types, accessibility, data dissemination products and the presentation format provided for end users. Section 3 presents a survey questionnaire developed to provide a better understanding of the utilization and usability of the products of DelDOT-TMC such as DelDOT Mobile App, WTMC 1380 AM travel advisory radio, DelDOT's public website, DelDOT's social media and DART transit service. Section 4 presents the results of a survey questionnaire to assess end user utilization and usability of DelDOT-TMC products and their personal experiences. Section 5 provides a summary, conclusion, and recommendations based upon the comparison data discussed in the previous sections.

\section{Ways of Communication to the Public}

DelDOT-TMC collects traffic data using both manual and automated methods [13]. Manual traffic counting is conducted using trained personnel and data collectors. Most studies of manual counts require small samples of data at any given location. Manual counts are used when the effort or expense associated with automated equipment is not justified or practical. Automated counts are collected using sensors, detectors, and cameras. Examples of automated data include traffic, roadway weather, and hydrological conditions [13].

After data is captured and processed, DelDOT-TMC disseminates real-time information to allow customers to make informed decisions regarding travel time and modal choice. Real-time monitoring is defined as the same instant that condition occurs. DelDOT considers real-time to be within a 5-minute time frame [13]. TMC uses real-time monitoring to provide customers with traffic and roadway weather information using various websites, DelDOT smartphone app (the DelDOT Mobile App), traffic advisory radio, and social media sites.

\subsection{Traffic and Roadway Weather Data from Various Websites}

DelDOT-TMC uses multiple websites to disseminate traffic and roadway weather data to the public. These websites include DelDOT's website, TMC Extranet, 
TMC "data map" website, TMC "Weather Summary" website, travel advisory radio, and social media sites such as Twitter, Facebook, and YouTube. Using these websites, DelDOT-TMC provides access to travel advisories and live traffic cameras.

\section{DelDOT's Public Website}

DelDOT's website offers real-time traffic and roadway weather information to the public. This website allows users to access traffic travel information through interactive travel maps, real-time schedule of DART transit, real-time travel advisories, events (i.e., road closures, beach traffic, special events), construction projects, news (including press release and traffic alerts), and workshops. This website also allows users to report road issues to DelDOT-TMC, listen to the live traffic advisory radio enabling users to receive information hands-free and access the social media sites through the website. DelDOT's public website also provides interactive Google maps, which display the location of traffic cameras, weather stations, and travel advisories and road closures throughout the state of Delaware.

\section{TMC Extranet Website}

DelDOT-TMC uses the TMC Extranet website to provide downloadable and printable traffic counts to the public. On this website, two tabs provide count studies data and documents for various preparedness plans. Under the "Count Studies" tab, the current extranet website contains downloadable PDF files of historical traffic data and traffic counts dating back to 2006. The site allows users to access various traffic data categories such as turning movement counts, classification counts, travel time runs, tube data, and radar data.

For each county, the TMC Extranet website also provides evacuation maps and information for all types of incidents and hazards. The "TMC Docs" tab includes preparedness plans including PDF format bridge closure, debris management, toll plaza, transportation incident and event management, and all hazard evacuation.

\section{TMC "Data Map" Website}

DelDOT-TMC uses TMC's "data map" website to provide traffic data. This website is not easily searchable by the public using regular web surfing. This website provides the following real-time data (Figure 1).

The TMC "data map" website provides real-time traffic volume through the "TMC Data Visualization" tab. This data is provided for each location (latitude and longitude) and counties (Kent, Sussex, and New Castle) within the state of Delaware. The website also allows users to view real-time travel time between two points on any given segment of a highway or street. It provides the base and current travel time in a side-by-side fashion. The "TMC data visualization" window offers travel time of 298 possible road segments.

The TMC "data map" website also provides users with access to live traffic cameras that are installed throughout Delaware's highways and intersections. The "Traffic Cameras" tab is a useful tool that allows the user to view real-time 


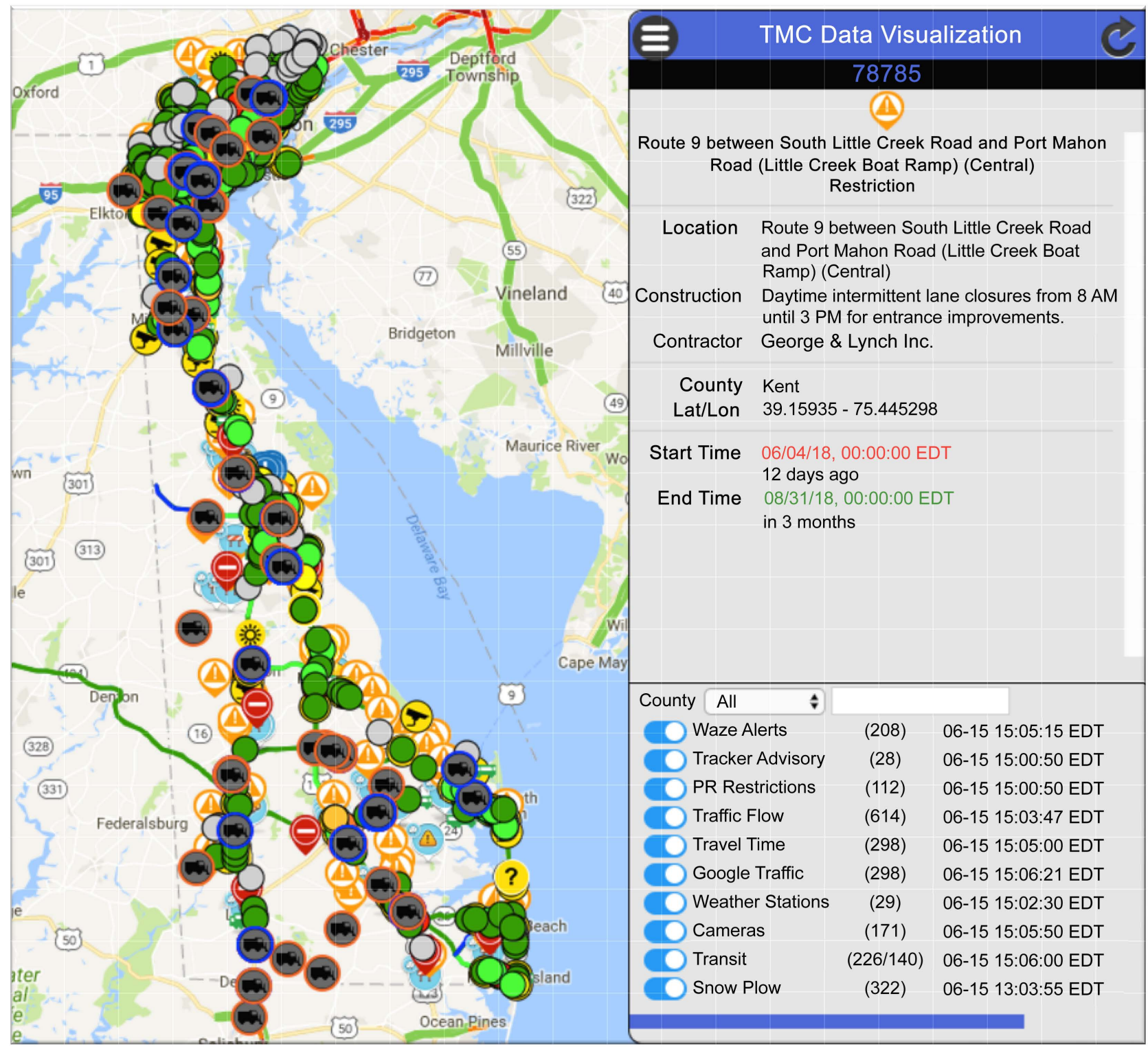

Figure 1. Types of Traffic data provided on DelDOT's TMC Website. (https://tmc.deldot.gov/datamap/).

traffic flow as well as any incident that may have occurred during that time. The TMC's “data map" website offers transit information such as DART bus schedules; where, it also informs the public about bus number, bus stop location, and bus arrival time for each county.

\section{TMC“ Weather Summary" Website}

In addition to traffic data, DelDOT-TMC also disseminates roadway weather data using its own "Weather Summary" website. In this website, a map-based Delaware weather monitoring system is provided. As per the department's website, the current Delaware weather and weather advisories are generated by the National Oceanic and Atmospheric Administration (NOAA); however, the site is not visible to the public.

In this "Weather Summary" website, the "Weather Station Summaries" tab 
allows users to access weather data by location. Users can expand each location to view all detailed real-time weather data. The "Weather Stations" tab provides weather data that includes surface temperature, subsurface temperature, air temperature, relative humidity, dew temperature, precipitation, visibility, wind speed, wind gust, and wind direction. The "Weather Charts" tab provides real-time weather information using (Time vs. Weather Data) charts for each weather station.

\subsection{Smartphone Application (DelDOT Mobile App)}

DelDOT-TMC administers the DelDOT smartphone application (DelDOT Mobile App), which is a breakthrough technology to optimize DelDOT's communication with the public. The DelDOT Mobile App can be used throughout an entire multimodal trip to provide information for drivers, transit riders, and pedestrians, such as road conditions, transit schedules [14] [15] [16] [17], work zones, lane restrictions or road closures [18].

DelDOT Mobile App provides real-time traffic and roadway weather information to the public [19]. The application allows users to access traffic travel information through interactive travel map, real-time bus schedule of DART transit, real-time travel advisories, events (i.e. road closures, beach traffic, special events), construction projects, news (including press releases and traffic alerts), and workshops. DelDOT Mobile App also allows users to report roadway conditions including traffic, potholes, debris, streetlights, and other road issues to DelDOT-TMC. The DelDOT Mobile App provides access to live traffic advisory radio with one-touch activation for hands-free access to traffic information, as well as access the social media pages. Also, through a new partnership, DelDOT and Waze share traffic data, which allows public access to Waze users to report incidents and traffic slowdowns. The DelDOT Mobile App provides travel map information so users can be informed regarding the latest traffic and roadway weather information before starting a trip. Although the DelDOT Mobile App provides real-time traffic information on the interactive travel map, it does not provide historical and real-time downloadable data.

\subsection{Traffic Data from Radio}

The traffic advisory radio station provides users with daily information on real-time traffic, weekly construction, transit, and public workshop announcement. Through DelDOT's designated AM radio frequency (WTMC 1380 AM), DelDOT-TMC broadcasts traffic advisory radio to update travelers on roadway and transit conditions. The WTMC 1380 AM radio station is a service of the DelDOT, broadcasting from a location near the city of Wilmington, Delaware with eleven repeater sites throughout the state. In addition to the radio broadcasting, this travel advisory communication can also be accessed through the DelDOT Mobile App. As a means of advertisement, signs are often posted to inform motorists to tune to the radio station for any traffic advisories. 


\subsection{Traffic Information through Social Media}

Social media sites such as Twitter, Facebook, YouTube, Flickr, and Blog have also been employed by DelDOT-TMC to disseminate traffic information. Users can access DelDOT's social media sites either directly from the DelDOT Mobile App or by going to the department's social media accounts. DelDOT informs and updates the public through social media by posting travel advisories to let Delawarean's know the current traffic conditions so they can make better informed decisions before heading out on the road.

\section{Expert Survey}

\subsection{Methodology}

DelDOT-TMC services are offered not only to its employees but also to the general public. To provide a better understanding of the utilization and usability of the products, a survey was employed to support this study [20] [21]. For this survey, the general public was chosen because they are the intended users for the products such as the DelDOT mobile application, social media sites, and travel advisory radio; where, having access to their feedback is critical. Since traffic and weather data are needed for evaluation and analysis of highway performance, the study also surveyed employees of DelDOT, related state agencies, and academic partners. For the survey, a specific evaluation criterion was not necessary since DelDOT's services are open to not only professionals and academia but also the general public. The questionnaire was distributed largely electronically via email. However, surveys were also distributed and collected via paper format.

As previously stated, DelDOT-TMC uses specialized equipment to collect traffic data and then uses various resources to provide information to the public. DelDOT-TMC provides information about traffic, weather, road condition, projects, etc., through the DelDOT Mobile App, travel advisory radio, DelDOT public website, and various social media sites. In today's society, there are various applications and websites that can also provide traffic and weather information, etc. Given the effort and resources that DelDOT-TMC spends on collecting real-time traffic and weather data and the availability of data resources outside of DelDOT, it was very important to conduct a survey to examine the use of the available services. For the survey, participants were asked several questions about the many available products of DelDOT-TMC and their personal experiences.

\subsection{Questions}

To achieve the survey's objective, a questionnaire was designed and prepared both in electronic and hard copy. The original questionnaire can be found in the appendix of this paper. The questionnaire has questions in six parts (general, DelDOT Mobile App, WTMC 1380 AM travel advisory radio, DelDOT public website, social media sites, and DART). The completion of the questions was designed to take approximately eight minutes. The survey group was informed that their responses would remain confidential. The following questions were asked: 
Following a question regarding the survey's objective, the first set of questions is listed as follows:

1) Which of the following represents your current status? Check boxes were provided for Delaware department of transportation employee, DE state agency employee, engineering consulting/private engineering firm employee, faculty, staff or student of UD, individual who uses Delaware roadways, and a fill-in space for indicating “other" status.

2) Approximately, how many miles do you drive per week on Delaware roads? The survey question asked for either a reported or estimated weekly mileage in miles.

Following the first question set, the second part asks nine questions about the utilization of DelDOT Mobile App. A respondent who does not use this smartphone application will only answer the first and last questions of this section.

3) Do you use the DelDOT's smartphone application, the DelDOT Mobile $A p p$ ? If Yes for $\mathrm{Q} 3$ continue If No skip to Q11.

4) How often do you use the DelDOT Mobile App? Single selection choices were provided for following with a fill-in space for other conditions: everyday, as needed, once in a while, almost never.

5) How comfortable are you using the DelDOT Mobile App even if it is against the law to use a cellphone in Delaware while driving? Single selection choices were provided for following with a fill-in space for other conditions: extremely comfortable, slightly comfortable, neither comfortable nor uncomfortable, slightly uncomfortable, extremely uncomfortable.

6) In your opinion, how user-friendly is the DelDOT Mobile App? Single selection choices were provided for following with a fill-in space for other conditions: very friendly, friendly, somewhat friendly, not at all friendly.

7) How accurate/informative is the DelDOT Mobile App? Single selection choices were provided for following with a fill-in space for other conditions: very accurate/informative, accurate/informative, somewhat accurate/informative, not at all accurate/informative.

8) What do you use the DelDOT smartphone application for? Please select all that apply.

Check boxes were provided for the following with a fill-in space for other conditions: to check on road conditions, to see DART transit schedules, to find out about work zones, lane restrictions or road closures, to learn about special events, to check roadway weather incidents, to check on traffic conditions, to find out about traffic delays, accidents, and other advisories, to find out the latest news and upcoming workshops, to see snowplow movement during snow events.

9) Based on your experience, would you recommend the DelDOT Mobile App to a friend? Single selection choices were provided for following with a fill-in space for other conditions: definitely will, probably will, probably will not, definitely will not.

10) Please tell us what improvement(s) you like to see in DelDOT Mobile App 
to use it more frequently. If No for Q3, go to Q11.

11) What is the reason you do not currently use the DelDOT Mobile App? Single selection choices were provided for following with a fill-in space for other conditions: No idea it exists, I tried it, did not work properly, I do not need to use it.

The third part asks eight questions about WTMC 1380 AM travel advisory radio. Respondents who do not use the radio for travel information will only answer the first and last question of the section.

12) Do you use the DelDOT's WTMC 1380 AM travel advisory radio? If Yes for Q 12 continue, If No skip to Q19.

13) How often do you use WTMC 1380 AM, the travel advisory radio, while driving on Delaware's Highways \& Streets? Single selection choices were provided for following with a fill-in space for other conditions: everyday, as needed, once in a while, almost never.

14) What is the typical reason for you listening to the WTMC 1380 AM? Please select all that apply. Check boxes were provided for the following with a fill-in space for other conditions: to find out about work zones, lane restrictions or road closures, to learn about special events, to check weather incidents, to check on traffic conditions, to find out about traffic delays, accidents, and other advisories.

15) What time of the day do you usually listen to WTMC 1380 AM? Single selection choices were provided for following with a fill-in space for other conditions: morning peak hours, afternoon peak hours, any time in the day, and any time at night.

16) How informative is the WTMC 1380 AM? Single selection choices were provided for following with a fill-in space for other conditions: Very informative, Informative, Somewhat informative, Not at all informative.

17) Based on your experience, would you recommend the WTMC 1380 AM radio to a friend? Single selection choices were provided for following with a fill-in space for other conditions: definitely will, probably will, probably will not, definitely will not.

18) Please tell us what improvement $(s)$ you like to see in DelDOT s WTMC 1380 AM radio to use it more frequently. If No for $Q 12$, go to $Q 19$.

19) What is the reason you do not currently use the DE travel advisory radio? Single selection choices were provided for following with a fill-in space for other conditions: no idea it exists, I tried it, did not work properly, I do not need to use it.

Part four asks seven questions about the utilization of DelDOT public website for traffic and roadway weather data inquiry before starting a trip or while driving. Respondents who answer "no" for the first question meaning they do not use the site will be directed to the last question of the section of the survey.

20) Do you visit DelDOT s public website for real-time traveler's information? If Yes for Q20 continue If No skip to Q26.

21) What information do you usually look for from the DelDOT public web- 
site? Please select all that apply. Check boxes were provided for the following with a fill-in space for other conditions: to check on road conditions, to see DART transit schedules, to find out about work zones, lane restrictions or road closures, to learn about special events, to check roadway weather incidents, to check on traffic conditions, to find out about traffic delays, accidents, and other advisories, to find out the latest news and upcoming workshops, to see snowplow movement during snow events.

22) How often do you visit DelDOT's public website to find out traffic data or real-time traveler's information? Single selection choices were provided for following with a fill-in space for other conditions: everyday, as needed, once in a while, almost never.

23) In your opinion, how informative is the DelDOT's public website? Single selection choices were provided for following with a fill-in space for other conditions: very informative, informative, somewhat informative, not at all informative.

24) Based on your experience, would you recommend the DelDOTs public website to a friend for travel information? Single selection choices were provided for following with a fill-in space for other conditions: definitely will, probably will, probably will not, definitely will not.

25) Please tell us what improvement(s) you like to see in DelDOT's public website to use it more frequently. If No for Q20, go to Q26.

26) What is the reason you do not currently use the DelDOT's public website? Single selection choices were provided for following with a fill-in space for other conditions: No idea it exists, I tried it, did not work properly, I do not need to use it.

The fifth part asks seven questions about the utilization of social media sites such as Twitter, Facebook, YouTube, Flickr, and Blog. A respondent who replies "no" to the first question of this section saying he/she does not use these sites will be directed to the last question of the section of the survey.

27) Do you use the DelDOT's Social media such as Twitter, Facebook, YouTube, Flickr, Blog? If Yes for Q27 continue If No skip to Q33.

28) What do you use the DelDOT social media for? Fill-in spaces were also provided for the utilization of social media sites.

29) How often do you use DelDOT's social media sites (Twitter, Facebook, YouTube, Flickr, Blog)? Single selection choices were provided for following with a fill-in space for other conditions: Everyday, As needed, Almost never.

30) Which DelDOT's social media site do you usually use for travel information? Single selection choices were provided for following with a fill-in space for other conditions: Twitter, Facebook, YouTube, Flickr, Blog.

31) How informative do you think the DelDOT social media sites? Single selection choices were provided for following with a fill-in space for other conditions: Very informative, Informative, Somewhat informative, Not at all informative.

32) Please tell us what improvement(s) you like to see in DelDOT's social me- 
dia sites to use them more frequently. If No for Q27, go to Q33.

33) What is the reason you do not currently use the DelDOT public website? Single selection choices were provided for following with a fill-in space for other conditions: No idea it exists, I tried it, did not work properly, I do not need to use it.

The last section asks five questions about the utilization of DART first state bus services and DelDOT-TMC's product used to check bus schedules.

34) Do you use the DART first state bus services? If Yes for Q34, continue; If No, go to Q38.

35) How often do you use DART first state bus services? Single selection choices were provided for following with a fill-in space for other conditions: everyday, as needed, almost never.

36) What service do you use to check DART's bus schedule? Single selection choices were provided for following with a fill-in space for other conditions: DelDOT Mobile App, DART's website, Printed Brochures.

37) Please tell us what improvement(s) you like to see in DelDOT's products to use them more frequently. If No for Q34, go to Q38.

38) What is the reason you do not currently use the DART service? The survey concluded with a question asking for other important concerns, comments or suggestions including reasons not using DART transit service.

\section{Survey Results}

The survey begins by examining the current employment status of the individuals taking the survey. As shown in Figure 2, the participants were offered six categories. The overall results revealed that $34 \%$ of the participants were engineering consulting/private engineering firm employees; $22 \%$ were faculty, staff, or students at University of Delaware; $19 \%$ were Delaware Department of Transportation (DelDOT) employees; 17\% were individuals who use Delaware roadways; $5 \%$ were in the others category (i.e. New Castle County employee); and the remaining $3 \%$ were Delaware state agency employees.

Survey Participant Makeup

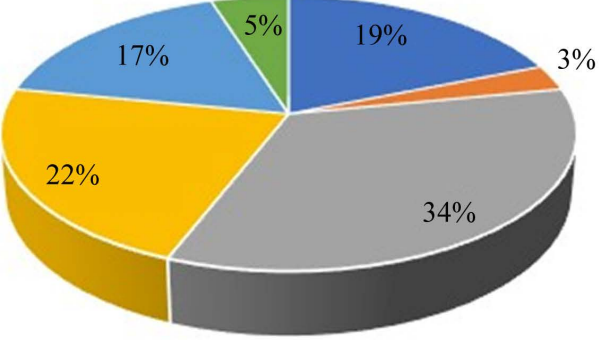

- DelDOT Employee

- DE State Agency Employee

- Consultant/Private Eng. Firm Employee

" UD Faculty, Staff or Student

- DE Roadway User

- Other(s)

Figure 2. Participants makeup. 
Participants were then asked to estimate their weekly driving mileage on Delaware roads. Figure 3 shows that the results revealed that $8 \%$ of the participants stated that they drove between 0 to 10 miles; $19 \%$ drove between 10 to 50 miles; $23 \%$ drove between 50 to 100 miles; $24 \%$ drove 100 to 200 miles and $23 \%$ of the participants stated that they drove more than 200 miles per week on Delaware roads. In addition, $4 \%$ stated mileage as other(s) and specified in narrative form.

\subsection{DelD0T's Smartphone/Mobile Application}

Smartphone applications are very popular in today's society. One of the services that DelDOT-TMC offers is the DelDOT's smartphone and mobile application. Participants were asked if they use the application and they simply had to state "yes" or "no". As shown in Figure 4, the results revealed that 33\% of the participants said "yes" and 67\% stated "no", they did not use DelDOT's smartphone or mobile application.

For those who used the applications, participants were asked how often and how comfortable were they in using the applications. Although it is against the law to use a cellphone in Delaware while driving, the overall results revealed that only $5 \%$ of the participants stated that they use the DelDOT Mobile App every day, but majority of the participants (43\%) use it "as needed". The results also revealed that at $30 \%$, majority of the participants stated that they were "neither comfortable nor uncomfortable" with using the applications. The lowest percentage was at $9 \%$ in which the participants stated that they were "slightly comfortable" in using the application while driving.

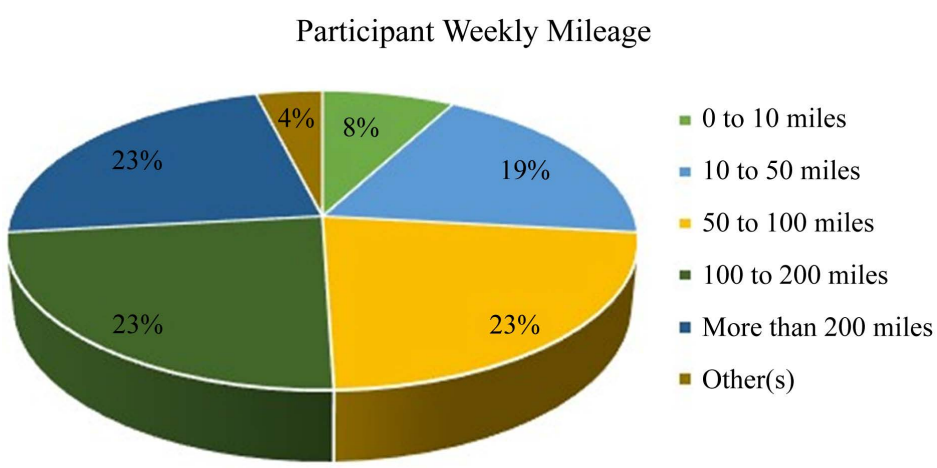

Figure 3. Weekly mileage driven by participants.

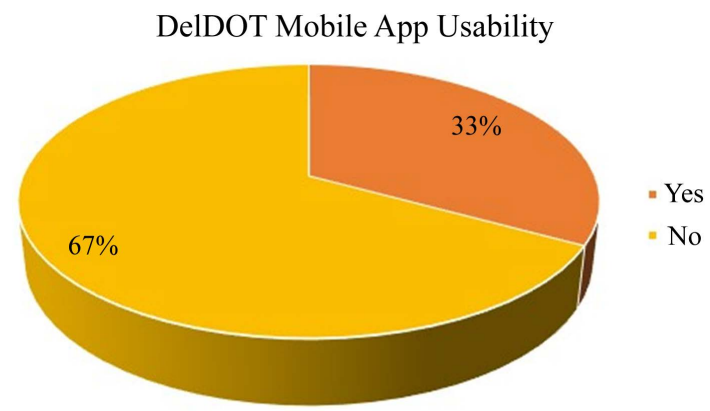

Figure 4. DelDOT mobile app usability by the general public. 
The participants were also asked how user-friendly and accurate or informative is the DelDOT Mobile App. 35\% of the participants stated that the DelDOT Mobile App was "friendly" and 35\% stated that it was "somewhat friendly". The lowest percentage was at $4 \%$ in which participants found that the application was "not at all friendly". When examining the accuracy of the DelDOT smartphone/mobile application, $57 \%$ of the participants found it to be "accurate/informative" while only $4 \%$ found it to be "very accurate/informative". Interestingly enough, none of the participants stated that they found the app to be "not at all accurate/informative".

Although some of the participants stated that they have or are using the DelDOT application, participants were asked to provide specific reasons on what they use the application for and if they would recommend it to a friend. Figure 5 shows that, at $25 \%$, majority the participants stated that they use the DelDOT smartphone application "To find out about traffic delays, accidents and other advisories". The lowest percentage was at 3\% in which participants stated they use the application "To learn about special events" and another 3\% also stated that they use the application "To find out the latest news and upcoming workshops".

The majority of the participants (59\%) stated that they "probably will" recommend the DelDOT mobile application to a friend while only $9 \%$ stated that they "probably will not" recommend the application.

For those who use the application, they were asked the following: "Please tell us what improvement(s) you like to see in DelDOT Mobile App to use it more frequently". The following recommendations were suggested that DelDOT should:

1) Provide more accurate information;

2) Improve camera feeds since the camera feeds freeze frequently and sometimes it does not show up at all;

3) Provide a link to road closure advisories to the Travel Map.

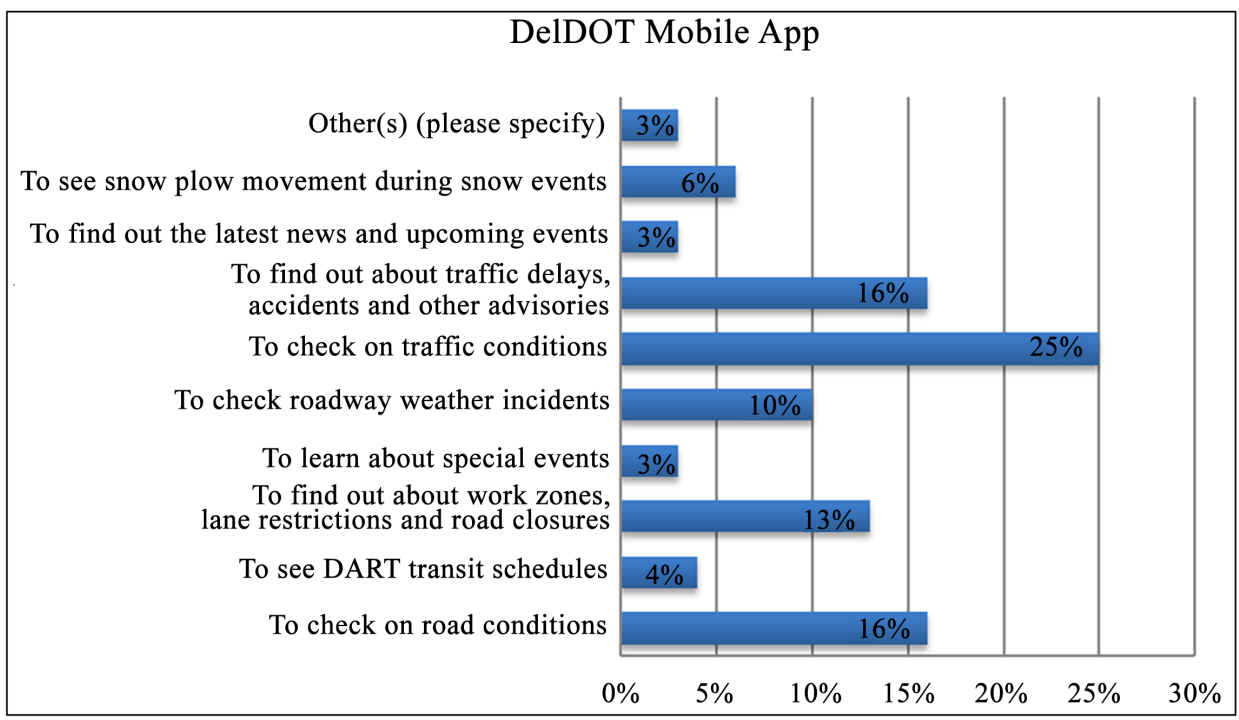

Figure 5. Types of information respondents get from DelDOT Mobile App. 
4) Make the application convenient to use while driving

For those individuals that stated that they do not use the DelDOT application, they were then asked, "What is the reason you don't currently use the DelDOT App?" Majority of the participants, 59\%, stated that they had "no idea it exists", while $39 \%$ stated "I don't need to use it".

The overall results revealed that majority of the participants did not use the DelDOT's smartphone or mobile application. Those who used the application used it as needed. Also, majority of the participants who used it found it to be friendly and accurate. The majority of the participants used the smartphone application to find out about traffic information such as accidents, delays, and other advisories. Although they had recommendations on how to improve their application, participants stated that they would recommend the mobile applications to friends. Those who did not use the DelDOT's smartphone application stated that they had no indication that the application existed.

\subsection{DelDOT's WTMC 1380 AM}

Another service that DelDOT-TMC offers is DelDOT's WTMC 1380 A.M. travel advisory radio, in which participants were asked if they are using the service. As shown in Figure 6 below, result of the survey revealed that $86 \%$ of the participants said "no" for listening to the travel advisory radio and only $14 \%$ said "yes".

Those who used the radio were asked the frequency of their usage, the typical reason of why they listened to it, and the time of day in which they listen to WTMC 1380 A.M. while driving on Delaware's highways and streets. At 46\%, majority of the participants revealed that they use the travel advisory radio "as needed" and the lowest percentage, which was at $8 \%$, stated that they "almost never" use it.

The results also revealed, as shown in Figure 7 below, that majority of the participants, at $31 \%$, listen to the radio "to check on traffic condition" and an additional 31\% listened "to find out about traffic delays, accidents and other advisories". The lowest was at $4 \%$ in which individuals stated that they listen to the radio "to check weather incidents".

WTMC 1380 AM Travel Advisory Radio

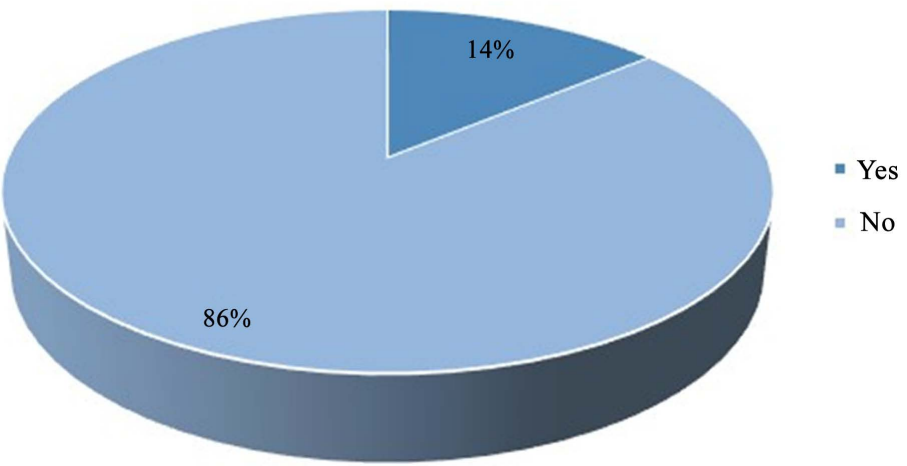

Figure 6. DelDOT's WTMC 1380 AM travel advisory radio usability. 


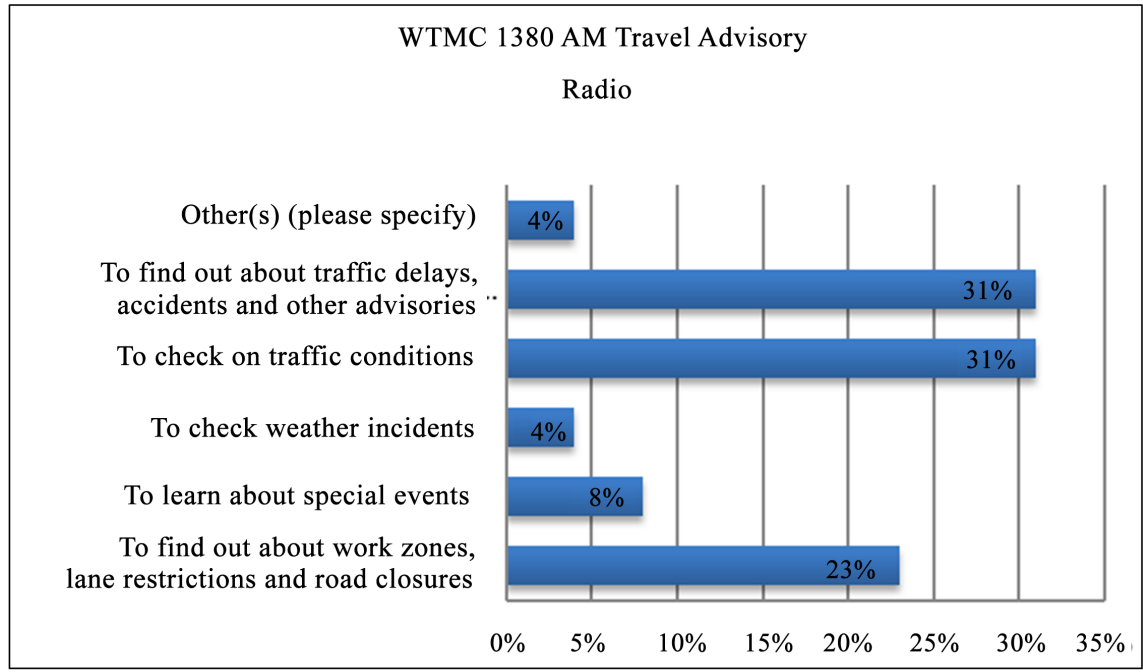

Figure 7. Types of information that respondents get from the radio.

As for the time in which participants listened to the radio, the results revealed that $60 \%$ stated that they listened to the radio "any time in the day". None of the participants stated that they use the radio "any time at night".

For those who used DelDOT's travel advisory radio, participants were asked how informative they found it to be and if they would recommend it to a friend. The result revealed that $50 \%$ of the participants stated that the radio was "somewhat informative". The lowest percentage was at $20 \%$, in which individuals indicated that they were "very informative". (0\%) None of the participants stated that it was "not at all informative". As for the recommendation, 50\% stated that they "probably will" recommend the WTMC 1380 AM radio to a friend but $20 \%$ of the participants said that they "probably will not".

Those who did not use the WTMC travel advisory radio were asked the reason behind their decision. At 51\%, majority of the participants stated, "I don't need to use it" while only $3 \%$ stated, "I tried it, didn't work properly".

Overall, the results revealed that majority of the participants did not use DelDOT's WTMC 1380 AM travel advisory radio because they stated that they did not need to use it. For those who did use the travel advisory radio, they used it as needed. Most of the participants listened to the radio anytime during the day and they mostly listened to find out traffic condition, delays, accidents, and advisories. Those who used the radio found it to be somewhat informative and they stated that they would probably recommend it to a friend.

\subsection{DelD0T's Public Website}

DelDOT-TMC has a public website that provides real-time traveler's information. Participants were asked if they visited DelDOT's public website and as shown in Figure 8, 70\% of the participants said "no" and 30\% said "yes".

Those who used the website were asked the type of information that they usually look for and how often they viewed the website to find out traffic data or real-time traveler's information. Figure 9 shows that participants had many 


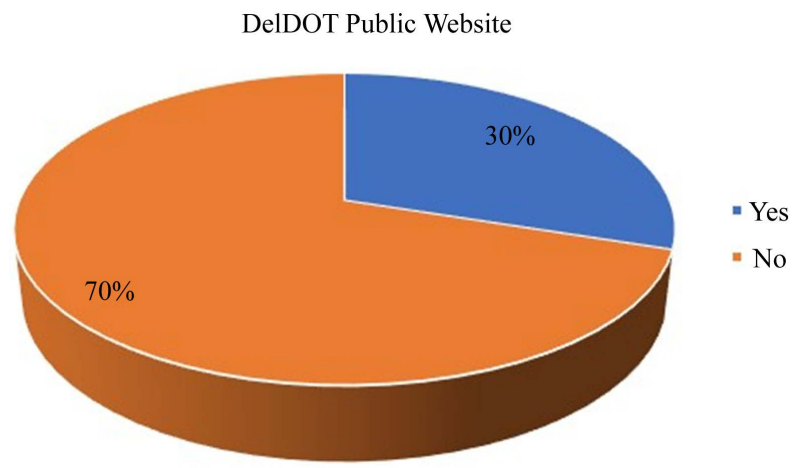

Figure 8. DelDOT’s public website visits.

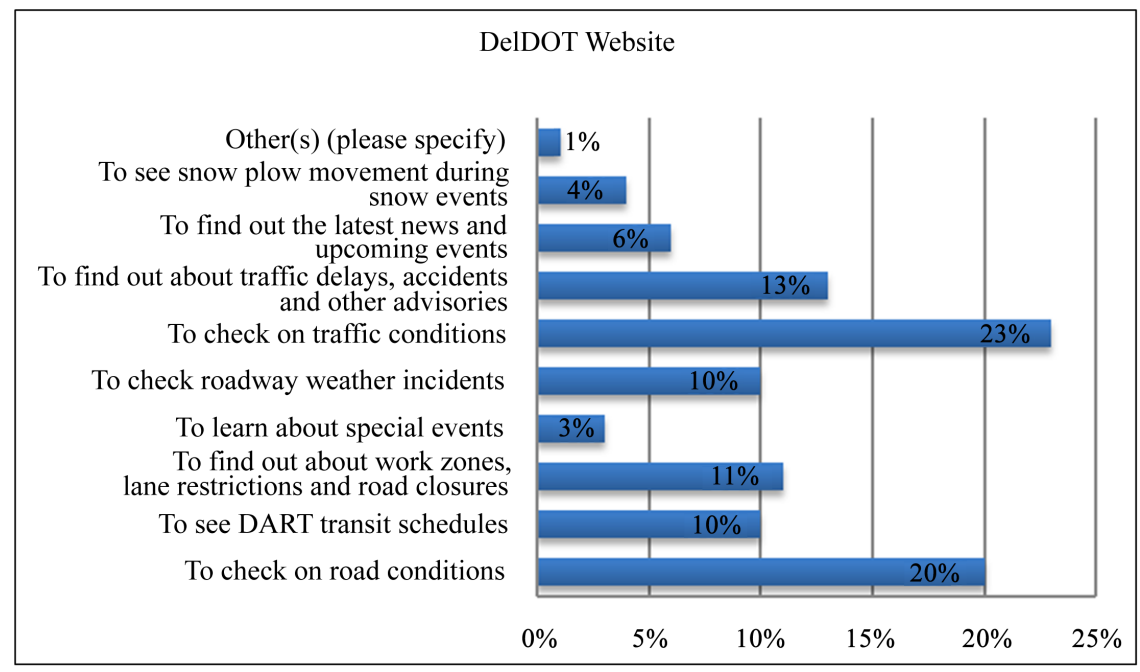

Figure 9. Types of information that participants get from DelDOT's website.

options and the results revealed that at $23 \%$, majority used the website "to check on traffic condition". The lowest percentage was at $3 \%$ in which the participants stated that they used the website "to learn about special events".

The results of the frequency in which participants viewed the website revealed that $50 \%$ visited DelDOT's public website "as needed" and only $9 \%$ viewed the website "every day".

Those who used the website where then asked how informative DelDOT's public website is and if they would recommend it to a friend for travel information. The results revealed that majority of the participants, $45 \%$, stated that the website was "informative" and $18 \%$ found it "very informative". Overall, all of the participants that used the website found it to be, in one-way or another, informative. The results also revealed that $64 \%$ of the participants stated that they "probably will" recommend the website to friends, $18 \%$ revealed that they "definitely will", and the remaining $18 \%$ stated that they "probably will not".

For the individuals who have stated that they do not currently use DelDOT's public website, they were then asked to provide a reason. The result revealed that $63 \%$ of the participants have stated, "I don't need to use it" while $2 \%$ stated, "I tried it, didn't work properly". 
The final result revealed that, majority of the participants did not visit DelDOT's public website for real-time traveler's information because they did not need to use it. Those who did use the website stated that they used it as needed to check on traffic condition. The participants also found DelDOT's public website to be informative and that they would probably recommend it to their friends.

\subsection{DelD0T's Social Media}

Among the previously mentioned services, DelDOT-TMC also offers traffic, weather, and much more through social media such as Twitter, Facebook, YouTube, Flickr, and Blog. As part of the survey, participants were asked if they used any of the social media sites that DelDOT offers. The results in Figure 10 revealed that $85 \%$ of the participants stated "no" they don't use DelDOT's social media sites and only $15 \%$ said "yes" they use at least one of DelDOT's social media.

Participants were then asked what they use the DelDOT social media sites for and how often they use it. The survey revealed that some of the participants specified that they wanted to find out traffic closures and office closings. Others were interested in the latest news, traffic updates, and current projects. One participant stated that they are simply trying to find out if anything interesting occurred. As for the frequency of usage, $67 \%$ of the participants stated that they use DelDOT's social media sites "as needed" and only $22 \%$ claimed that they use it "every day".

Those who used DelDOT's social media sites were also asked which of DelDOT's social media site did they usually use to obtain travel information and how informative did they find the sites to be. The results revealed that $57 \%$ of the participants stated that they use DelDOT's Facebook, 36\% used Twitter; and only 7\% used YouTube. As shown in the chart in Figure 11, none of the participants revealed that they use DelDOT's Flickr or Blog to obtain travel information.

Regardless which of DelDOT's social media sites that the participants used, $56 \%$ found the sites to be "informative" and $22 \%$ stated that it was "very Informative" and the remaining $22 \%$ stated that it was "somewhat informative".

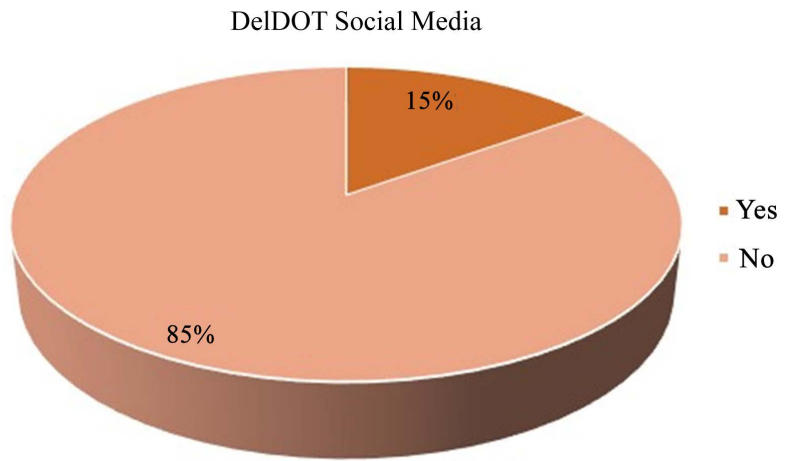

Figure 10. DelDOT's social media visit by the public. 


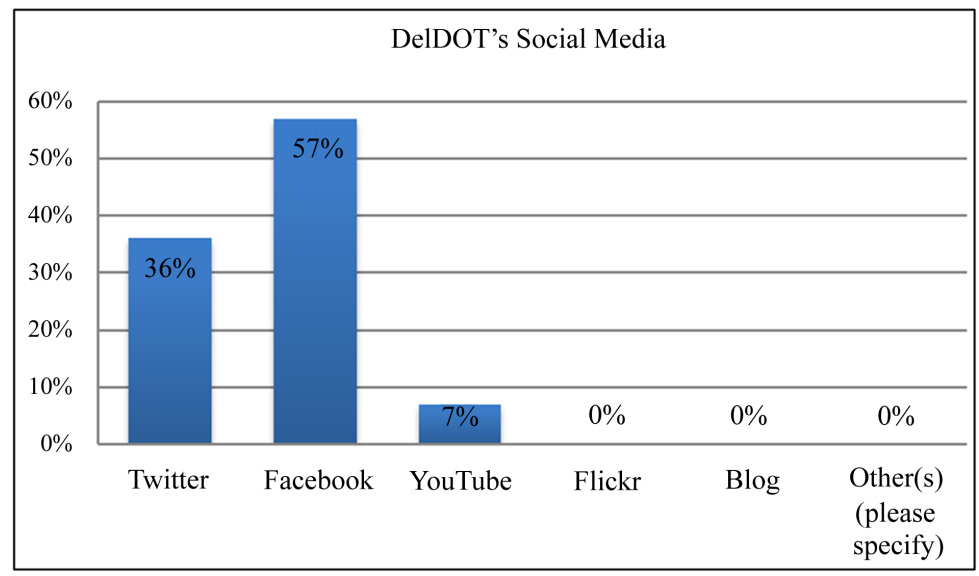

Figure 11. DelDOT's social media visits by the participants (in \%).

Those who did not use any of DelDOT's social media sites were asked to provide a reason for their decision not to visit these social media sites. The results revealed that $72 \%$ of the participants stated, "I don't need to use it" and $3 \%$ stated, "I tried it, didn't work properly".

The overall results revealed that majority of the participants did not use DelDOT's social media sites. Those who did not use the social media sites stated that they did not need to use it. The participants that used it to obtain traffic information as needed and they found it to be informative. Out of all DelDOT's social media sites, Facebook was most often used.

\subsection{DART}

One of the most common services that DelDOT offers is the DART first state bus services. A part of the survey asked participants if they use DART. The results shown in Figure 12 revealed that $89 \%$ of the participants' stated "no" they don't use the service and $11 \%$ said "yes".

For those who used DART bus, participants were asked how often they used DART and what services they used to check bus schedule. Overall, the results revealed that $50 \%$ of the participants stated that they use DART bus services "everyday" and 13\% stated that they "almost never" use it. In addition, $43 \%$ stated that they use the DelDOT mobile app to check bus schedule and the lowest percentage was at $29 \%$, in which individual revealed that they use "printed brochures". Interestingly enough, as shown in Figure 13 below, the results also revealed that $0 \%$, none of the participants used" DART's website" to check bus schedules.

Those who stated that they did not use DART first state bus were asked to provide a reason. Majority of the participants revealed that they did not use DART services because they have their own vehicle. Others have stated that it is inconvenient, and a few said they did not have bus services near their homes.

Overall, majority of the participants do not use the DART bus services mainly because they have their own vehicles. Majority of those who use the bus stated that they use it on a daily basis. To check the bus schedule, most participants use 
the DelDOT mobile app.

\subsection{Summary}

In summary, the use of DelDOT-TMC products and services is relatively low; where, it was discovered that a majority of the participants did not use DelDOT's products and services. Figure 14 below, highlights the summarized results from the survey regarding use of DelDOT-TMC products and services; where, there is an average $21 \%$ use across the studied DelDOT-TMC products and services (with a standard deviation of 10.1).

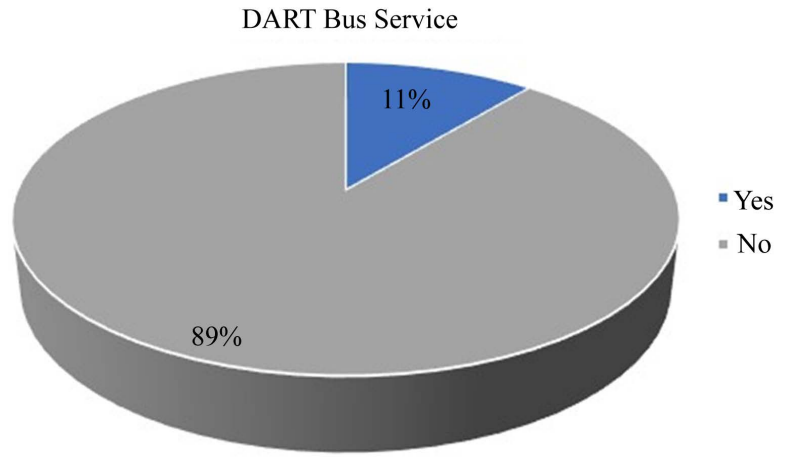

Figure 12. DART first state bus service usability.

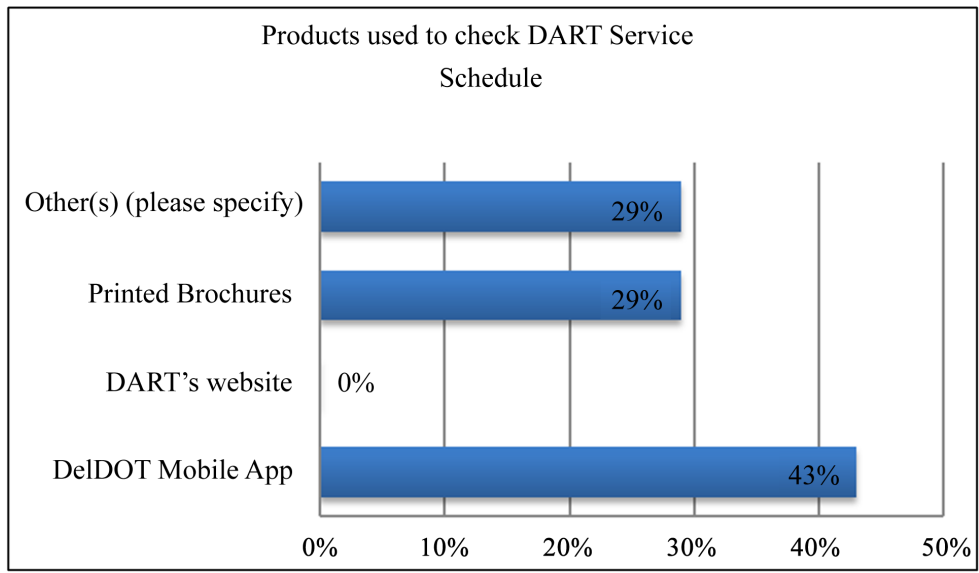

Figure 13. Products used to check DART bus schedules (in \%).

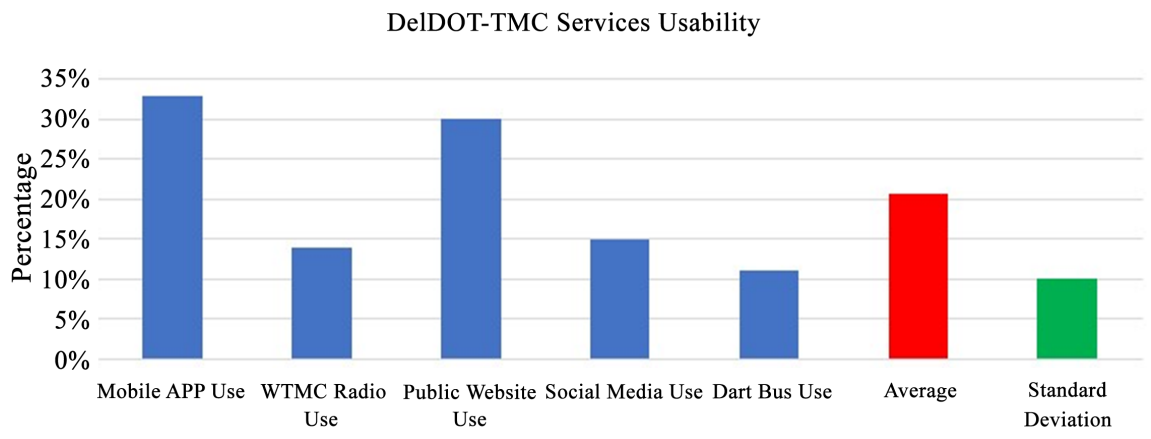

Figure 14. Summary of use of DelDOT-TMC products and services. 


\section{Conclusions}

The purpose of this survey was to examine the usability, if any, of DelDOT's website, social media sites, radio, smartphone application, and DART services. The survey revealed interesting results. Overall, it was discovered that a majority of the participants did not use DelDOT's products and services. Those who did not use the services stated that either they did not have a need for it, or they did not know it existed. The participants that used the different services did so mainly to obtain traffic information. These individuals also used DelDOT's services as needed and most found it informative and friendly to use. Out of all of the mentioned DelDOT services, it was discovered that participants mostly used DART bus services.

DelDOT-TMC is an important part of Delaware's transportation industry. Real-time and historical traffic data, as well as roadway weather data, is essential information not only for the public but also for academia, students, engineering consultants, and the different divisions in DelDOT. Although DelDOT-TMC has provided a lot of travel information through the previously mentioned sources, there is certainly room for improvement. The following are suggestions to DelDOT-TMC on possible improvements based on the research results:

1) Advertise the products so more people are aware that they exist;

2) Provide accurate and more information through all the products;

3) Improve the database to allow the public to download or export the collected data in multiple formats;

4) Expedite the approval process for users or provide free access to the website;

5) Provide real-time and historical data on all of the sites so that users can search for information based upon a specific range of time and date;

6) Provide transportation data in other formats in addition to PDF files;

7) Offer easier access to the "TMC Data Map" and "TMC Weather Summary" websites;

8) Produce an automatic broadcast traffic advisory system through the DelDOT Mobile APP in compliance with Delaware's hands-free law.

As the number of drivers continues to increase, so will the need for traffic and road weather information. Therefore, more research will be needed to improve our transportation system. This study was based upon the current resources that DelDOT-TMC offered to the public and the survey result conducted by the study; however, future work is recommended to obtain more information via coordination with DelDOT-TMC, directly. By interviewing or communicating with DelDOT-TMC staff directly and securing access to additional resources, it may be possible to gather and assess vital information that is not currently available online. Although this study was conducted for the State of Delaware, other states, regional and private transportation agencies may use the methods explained in this paper to make a comprehensive assessment of the usability of their own traffic-related products. 


\section{Acknowledgements}

This work was partially supported by the Delaware Center for Transportation (DCT) which is co-sponsored by the University of Delaware and the Delaware Department of Transportation. The authors express their sincere gratitude to DCT for providing their extensive data sources.

\section{Conflicts of Interest}

The authors declare no conflicts of interest regarding the publication of this paper.

\section{References}

[1] Jia, A., Zhou, X., Li, M., Rouphail, N. and Williams, B. (2011) Incorporating Stochastic Road Capacity into a Day-to-Day Traffic Simulation and Traveler Learning Framework: Model Development and Case Study. Transportation Research Record: Journal of the Transportation Research Board, 2254, 112-121. https://doi.org/10.3141/2254-12

[2] Zhou, X., Rouphail, N. and Li, M. (2011) Analytical Models for Quantifying Travel Time Variability Based on Stochastic Capacity and Demand Distributions. Transportation Research Board 90th Annual Meeting, Washington DC, 23-27 January 2011, No. 11-3603.

[3] Li, M., Zhou, X. and Rouphail, N. (2011) Planning-Level Methodology for Evaluating Traveler Information Provision Strategies under Stochastic Capacity Conditions. Transportation Research Board 90 th Annual Meeting, Washington DC, 23-27 January 2011, No. 11-3002.

[4] Suarez, R., Faghri, A. and Li, M. (2014) Evaluation of the Accuracy and Automation of Travel Time and Delay Data Collection Methods. Journal of Transportation Technologies, 4, 72-83. https://doi.org/10.4236/jtts.2014.41007

[5] Berzina, L., Faghri, A., Shourijeh, M.T. and Li, M. (2014) Development of a Post-Processing Automation Procedure for the GPS-Based Travel Time Data Collection Technique. Journal of Transportation Technologies, 4, 63-71. https://doi.org/10.4236/jtts.2014.41006

[6] Li, M. and Faghri, A. (2016) Applying Problem-Oriented and Project-Based Learning in a Transportation Engineering Course. Journal of Professional Issues in Engineering Education and Practice, 142, Article ID: 04016002. https://doi.org/10.1061/(ASCE)EI.1943-5541.0000274

[7] Li, M., Rouphail, N.M., Mahmoudi, M., Liu, J. and Zhou, X. (2017) Multi-Scenario Optimization Approach for Assessing the Impacts of Advanced Traffic Information under Realistic Stochastic Capacity Distributions. Transportation Research Part C: Emerging Technologies, 77, 113-133. https://doi.org/10.1016/j.trc.2017.01.019

[8] Li, M., Zhou, X. and Rouphail, N.M. (2017) Quantifying Travel Time Variability at a Single Bottleneck Based on Stochastic Capacity and Demand Distributions. Journal of Intelligent Transportation Systems. Technology, Planning, and Operations, 21, 79-93. https://doi.org/10.1080/15472450.2016.1163639

[9] Schroeder, B.J., Cunningham, C.M., Findley, D.J., Hummer, J.E. and Foyle, R.S. (2010) Manual of Transportation Engineering Studies. Institute of Transportation Engineers, Washington DC.

[10] Berzina, L., Faghri, A., Shourijeh, M. and Li, M. (2013) Evaluation of Travel Time Data Collection Techniques: A Statistical Analysis. International Journal of Traffic 
and Transportation Engineering, 2, 149-158.

https://doi.org/10.5923/j.ijtte.20130206.03

[11] Ozden, A., Faghri, A. and Li, M. (2016) Using Knowledge-Automation Expert Systems to Enhance the Use and Understanding of Traffic Monitoring Data in State DOTs. Procedia Engineering, 145, 980-986.

https://doi.org/10.1016/j.proeng.2016.04.127

[12] Vandervalk-Ostrander, A. (2009) AASHTO Guidelines for Traffic Data Programs. AASHTO, Washington DC.

[13] DelDOT (2017) Delaware Department of Transportation Integrated Transportation Management Strategic Plan. DelDOT, Dover.

[14] Vaughan, M.L., Faghri, A. and Li, M. (2016) An Interactive Expert System Based Decision Making Model for the Management of Transit System Alternate Fuel Vehicle Assets. Intelligent Information Management, 9, 1-20.

https://doi.org/10.4236/iim.2017.91001

[15] Scott, M., Kelly, C., Collins, E., Lewis, J., Faghri, A. and Li, M. (2017) Research of Viable Attributes and Potential to Integrate Curbside Intercity Buses. Transportation Research Board 96th Annual Meeting, Washington DC, 8-12 January 2017.

[16] Vaughan, M.L., Faghri, A. and Li, M. (2018) Knowledge-Based Decision-Making Model for the Management of Transit System Alternative Fuel Infrastructures. International Journal of Sustainable Development \& World Ecology, 25, 184-194. https://doi.org/10.1080/13504509.2017.1333541

[17] Shahpar, A., Faghri, A. and Li, M. (2018) Emission and Life-Cycle Assessment of Alternative-Fuel Buses: A Case Study of the Delaware Authority of Regional Transit. International Journal of Sustainable Development \& World Ecology, 25, 290-302. https://doi.org/10.1080/13504509.2017.1390794

[18] Li, M., Faghri, A. and Fan, R. (2017) Determining Work Zone Lane Capacities along Multilane Signalized Corridors. Delaware Center for Transportation, Newark.

[19] DeCoursey, W.J., Scott, M.S., Pragg, S., Kirschling, N.W., Heath, G.A. and Inman Perry, R. (2014) Research to Assess Branding and Marketing Needs for DelDOT TMC's Real-Time Traveler Information System. Institute for Public Administration, Newark.

[20] Williams, B.M. and Guin, A. (2007) Traffic Management Center Use of Incident Detection Algorithms: Findings of a Nationwide Survey. IEEE Transactions on Intelligent Transportation Systems, 8, 351-358. https://doi.org/10.1109/TITS.2007.894193

[21] Humphrey, S., Faghri, A. and Li, M. (2013) Health and Transportation: The Dangers and Prevalence of Road Rage within the Transportation System. American Journal of Civil Engineering and Architecture, 1, 156-163.

[22] Li, M., Zhou, X. and Rouphail, N. (2011) Quantifying Benefits of Traffic Information Provision under Stochastic Demand and Capacity Conditions. 2011 14th International IEEE Conference Intelligent Transportation Systems (ITSC), Washington DC, 5-7 October 2011. https://doi.org/10.1109/ITSC.2011.6082843

[23] Frey, R., Faghri, A. and Li, M. (2014) Development of an Expert System for Effective Countermeasure Identification at Rural Unsignalized Intersections. Transportation Research Board 93rd Annual Meeting, Washington DC, 12-16 January 2014.

[24] Hamad, K., Faghri, A. and Li, M. (2015) Forecasting Model for Vehicular Demand: An Alternative Methodology in the Context of Developing Countries. The Journal of Developing Areas, 49, 125-143. https://doi.org/10.1353/jda.2015.0006 